Cartas al editor

\title{
Necrólisis epidérmica tóxica después de tratamiento con paroxetina
}

\author{
P. Wolkenstein ${ }^{1}$, D. Cremniter ${ }^{2}$ y J. C. Roujeau ${ }^{1}$

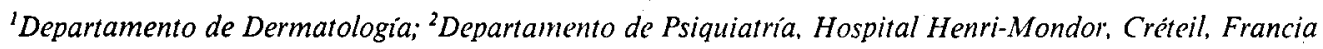

Los inhibidores de la recaptación de la serotonina fluoxetina, fluvoxamina y paroxetina son fármacos antidepresivos de segunda generación. Sus indicaciones son sobre todo los síndromes depresivos, en los que su eficacia es comparable a la de los antidepresivos tricíclicos. Otras indicaciones son la bulimia, en la que la fluoxetina favorece la pérdida de peso, trastornos adictivos como el alcoholismo, trastornos obsesivo-compulsivos y trastornos de control de impulsos. La fluvoxamina se puede prescribir en Francia desde 1986, seguida por la fluoxetina en 1988 y, más recientemente, por la paroxetina en 1993. Se supone que los inhibidores de la recaptación de la serotonina son seguros y se toleran bien, aunque algunos estudios han comunicado intentos de suicidio durante estos tratamientos en respuesta a una mayor ansiedad. Informamos aquí sobre la primera paciente, que sepamos, que desarrolló una necrólisis epidérmica tóxica (NET) grave después del inicio de la paroxetina.

Una mujer de 23 años sin historia familiar de enfermedades de la piel fue hospitalizada por una depresión con rasgos psicóticos. Se prescribieron dosis diarias de $40 \mathrm{mg}$ de ciamepromacina, $3 \mathrm{mg}$ de trihexifenidilo y $30 \mathrm{mg}$ de paroxetina. Dos semanas después (día 14), desarrolló una extensa erupción febril con grandes vesículas con implicación de la membrana mucosa. Dos días después (día 16) fue derivada a nuestra institución. En la admisión, presentaba una separación epidérmica del tronco, rostro y miembros proximales que implicaba el $35 \%$ del área de la super- ficie corporal (ASC). El signo de Nikolsky fue positivo en grandes áreas. Estaban presentes dolorosas erosiones orales, oculares y genitales, y la temperatura era de $40^{\circ} \mathrm{C}$. El examen histológico de la piel mostró una necrosis total de la epidermis consistente con el diagnóstico de NET. La inmunofluorescencia directa fue negativa. Amplias investigaciones para virus y Mycoplasma pneumoniae descartaron una NET excepcional inducida por infección. Rápidamente, la paciente desarrolló una alteración de la función pulmonar. La broncoscopia confirmó una destrucción limitada del epitelio traqueal y bronquial. El día 34 , fue dada de alta. Un mes después, presentaba áreas de piel sin pigmentación y una fotofobia persistente.

\section{Discusión}

Segun el método utilizado por el sistema de vigilancia farmacológica francés, era verosimil la culpabilidad de la ciamepromacina, el trihexifenidilo y la paroxetina. Trihexifenidilo y ciamepromacina se pueden prescribir desde las décadas de 1950 y 1970 , respectivamente, frente a 1993 para la paroxetina. En las bases de datos que incluyen Medline, nunca se ha implicado a estos tres fármacos como inductores de NET (Srebnik et al, 1991). Debido a su uso más reciente, la paroxetina șe consideró más sospechosa. Así, que sepamos, comunicamos el primer

Wolkenstein P, Cremniter D, Roujeau JC. Toxic epidcrmal necrolysis after paroxetine treatment. Eur PSychiatry 1995; 10: 162 
caso de NET observado después de tratamiento con paroxetina.

Los fármacos antidepresivos de segunda generación, en especial los inhibidores de la recaptación de la serotonina, se suponen seguros (Freeman et al, 1991). Sin embargo, se ha comunicado ya un caso de NET y un caso de síndrome de Stevens-Johnson después de tratamiento con fluoxetina (Bodokh et al, 1991; Wagner et al, 1992). Desde 1986, se comunicó al sistema francés de vigilancia farmacológica un caso de síndrome de Stevens-Johnson, con la fluvoxamina como responsable probable, pero no se investigó la posibilidad de infección por herpes y micoplasma. Comunicamos un caso de NET después de tratamiento con fluvoxamina (Wolkenstein et al, 1993). Así, los inhibidores de la recaptación de la serotonina parecían ser posibles inductores de reacciones cutáneas adversas al fármaco que amenazan la vida. Estos fármacos se están convirtiendo en los antidepresivos más vendidos. Por ejemplo, la fluoxetina es uno de los fármacos antidepresivos más prescritos en Francia, re- presentando en torno al $20 \%$ de los antidepresivos prescritos en 1991 y 1992 (Menard et al, 1992). Los efectos secundarios graves pueden ser poco frecuentes, pero potencialmente muy graves.

Bodokh I, Lacour Ph, Rosenthal E et al. Syndrome de Lyell ou nécrolyse épidermique toxique et syndrome de Stevens-Johnson après traitement par fluoxétine. Thérapie 1992; 47: 441.

Freeman CP. Fluvoxamine: clinical trials and clinical use. J Psychiatr Neurosci 1991, 16: 19-25.

Menard G, Allain H, Beneton C, N'Guyen JM. Enquête épidémiologique sur la prescription d'antidépresseurs. Psychol Med 1992; 24: 1550-4.

Srebrnik A, Hes JP, Brenner S. Adverse cutaneous reactions to psychotropic drugs. Acta Derm Ven (Stockh) 1991; 71 (suppl 158): 3-12.

Wagner W, Plekkenpol B, Gray TE, Vlaskamp H, Essers $\mathrm{H}$. Review of fluvoxamine safety database. Drugs 1992; 43 (suppl 2): 48-54.

Wolkenstein P, Revuz J, Dieh JL, Langeron O, Roupie E, Machet $L$. Toxic epidermal necrolysis after fluvoxamine. Lancet 1993; 31: 304-5. 